\title{
Blastocistose: controvérsias e indefinições
}

\author{
Blastocystosis: controversy and indefinedness \\ Vicente Amato Neto', Ruth Semira Rodríguez Alarcón', Erika Gakiya1, Rita Cristina Bezerra1, \\ Cláudio Santos Ferreira ${ }^{1}$ e Lúcia Maria Almeida Braz ${ }^{1}$
}

\begin{abstract}
Resumo Blastocistose é a infecção causada pelo Blastocystis hominis. Está relacionada com várias controvérsias e indefinições, sem dúvida muito importantes sobretudo pelas implicações médico-assistenciais que suscitam. A propósito, pendência expressiva diz respeito à patogenicidade do referido protozoário, que precisa ser categoricamente definida. Ao lado dessa particularidade outros assuntos exigem elucidações através de pesquisas bem conduzidas, para que a blastocistose fique devidamente situada no contexto da saúde pública. Aspecto também digno de atenção é o diagnóstico pelo exame parasitológico de fezes, necessariamente executável por meio de métodos adequados, como o direto e os permanentes, exemplificados pelos que usam a a hematoxilina férrica ou a tionina. O emprego de técnicas impróprias propicia resultados falsos-negativos, conturbando o aconselhável bom conhecimento da real participação do microrganismo em questão.
\end{abstract}

Palavras-chaves: Blastocistose. Blastocystis hominis. Controvérsias e indefinições. Orientação para o diagnóstico.

Abstract Blastocystosis is the infection caused by Blastocystis hominis. It is associated with frequent and unquestionably very important controversy and lack of definition, above all due to its implications for general assistance and medical care. In that connection, there is considerable disagreement on the subject of the pathogenicity of this protozoan, which should be categorically defined. Other aspects besides the above, require clarification through results from well conducted studies aiming at attributing Blastocystis hominis a proper role within the context of public health. Another matter worthy of attention is the diagnostic value of the parasitological stool examination, with the proviso that it is adequate, as are fecal smears suspended in saline solution or permanent mounts stained with iron hematoxylin or thionine. The use of inadequate techniques tends to produce false negative results, thereby impeding investigation into the real importance of this microorganism.

Key-words: Blastocystosis. Blastocystis hominis. Controversy and undefinedness. Diagnostic clues.

A blastocistose, infecção devida ao Blastocystis hominis, está relacionada com várias controvérsias e indefinições. É comum verificar que expressivo número de médicos, patologistas e profissionais que exercem atividades no âmbito da saúde pública desconhecem aspectos da participação desse protozoário e essa situação faz com que esclarecimentos sejam reiteradamente solicitados, o que caracteriza a ocorrência de inseguranças ou de adoções de condutas inadequadas em tarefas assistenciais.

É importante e desejável que conhecimentos sobre blastocistose fiquem satisfatoriamente divulgados, para evitar procedimentos impróprios e auxiliar no sentido de tornar mais ampla a difusão de corretas particularidades vinculadas a tal microrganismo.

Entre as controvérsias e indefinições lembramos a seguir as com maior freqüência mencionadas: não está categoricamente definido se o $B$. hominis é patogênico, convindo referir que colonoscopia demonstra que não invade tecidos; há quem julgue prudente considerá-lo como potencialmente patogênico; presentemente, chega a ser tido como oportunista em imunodeprimidos e, a propósito, grande quantidade encontrada em exame parasitológico de fezes respalda, segundo alguns

\footnotetext{
1. Laboratório de Investigação Médica do Departamento de Parasitologia do Hospital das Clínicas da Faculdade de Medicina da Universidade de São Paulo, São Paulo, SP.

Endereço para correspondência: Prof. Vicente Amato Neto. Lab. de Investigação Médica Parasitologia/ HC/FM/USP. Av. Dr. Enéas de Carvalho Aguiar 470, 05403-000 São Paulo, SP.

Tel: 11 3066-7042, Fax: 11 3081-8144

e-mail:amatonet@usp.br

Recebido para publicação em 6/5/2003

Aceito em 12/6/2003
} 
patologistas, essa possibilidade; parece prematura a atitude dos que afirmam que se trata de comensal; a classificação taxonômica ainda não ficou cabalmente assentada; persiste dificuldade para aplicar à blastocitose os postulados de Koch; a falta de modelos experimentais impede melhores estudos acerca da patogenicidade; autoinfecção é interpretada como possível; a transmissão por enquanto requer esclarecimentos e os fatores de risco atinentes a ela são em grande parte desconhecidos.

Com o intuito de eventualmente conceder expressividade à blastocistose, é rememorado o que se passou com Cryptosporidium e microsporídios, por exemplo, antes encarados como não-patogênicos e, no momento, reconhecidos como motivadores de acometimentos dignos de atenção, sobretudo no contexto dos oportunistas.

De acordo com o que é habitualmente mencionado a infecção pelo $B$. hominis pode motivar manifestações clínicas, persistentes durante três a dez dias ou até no decurso de períodos bem maior, admitindo-se que permanece nos intestinos em períodos que vão de semanas a anos. Todavia, a presença do protozoário freqüentemente não gera distúrbios, em contexto assintomático. Os acontecimentos, quando sintomáticos, compõem o que faz parte de gastroenterite, sendo viável então a ocorrência de dor abdominal, prurido anal, flatulência, meteorismo, náusea, vômito e diarréia de intensidade variável, sem presença de leucócitos ou sangue nas fezes.

Uma circunstância é bastante significativa sob os pontos de vista médico-assistencial e sanitário, no campo da saúde pública. $O$ encontro do $B$. hominis em fezes não garante que ele seja o responsável por doença em fase de elucidação etiológica, porquanto persiste dúvida acerca da patogenicidade, como já salientamos. Por isso, é necessário procurar cuidadosamente a possível ação determinante de outra causa, por meio de múltiplas medidas, num labor realmente intensivo. Diarréia e sinais ou sintomas de gastroenterite dependem de muitos motivos, infecciosos ou não. Assim, atribuir à blastocistose determinada situação digna de esclarecimento é hoje tarefa plena de contratempos.

A distribuição geográfica da blastocistose provavelmente é global. Porém, acontece mais comumente nos países em desenvolvimento das regiões tropical e subtropical, comparecendo, no entanto, conforme cifras marcantes também em nações desenvolvidas. Por vezes diz respeito a turistas e já foi responsabilizada por surtos ou acontecimentos comprovados em creches e day-care-centers.

No diagnóstico pretendemos prestar informações objetivamente orientadoras. De início destacaremos o comportamento esdrúxulo de patologistas que ao liberarem resultados de exames parasitológicos de fezes nunca registram o encontro do $B$. hominis porque valorizam não-patogenicidade de forma categórica, a despeito disso ainda corresponder a assunto em etapa de esclarecimento. Outro aspecto é a convicção de alguns profissionais que julgam o diagnóstico difícil e sugerem que, em certas oportunidades, impõe-se repetição das análises.

Com destaque salientamos que para evidenciar o $B$. hominis em fezes só servem métodos apropriados, como o direto e preparações permanentes exemplificadas pelas colorações por meio da hematoxilina férrica ou da tionina. A água e diversas soluções lisam o protozoário, decorrendo disso resultados falsos-negativos. Para documentar essa circunstância usaremos o que verificamos em tarefa assistencial que recentemente desenvolvemos.

Examinamos as fezes de 307 crianças, com sete a doze anos de idade, matriculadas em escola situada em bairro periférico da cidade de São Paulo e residentes nessa região, contando com boas condições sob o ponto de vista sanitário, das quais fazem parte disponibilidade de água potável e rede de esgotos. Utilizamo-nos dos métodos direto, de Faust e colaboradores e da sedimentação espontânea em água, executando também coloração pela hematoxilina férrica. Encontramos os seguintes protozoários ou ovos de helmintos: Entamoeba coli- 75 (24,4\%); Endolimax nana - 59 (19,2\%); Blastocystis hominis - 30 (9,8\%); Giardia lamblia - 21 (6,8\%); Entamoeba histolytica ou dispar, sem determinação da espécie - 14 (4,6\%); Trichuris trichiura-9 (2,9\%); Ascaris lumbricoides - 7 (2,3\%); Enterobius vermicularis-7 (2,3\%); ancilostomídeo - $3(0,98 \%)$; lodamoeba bütschlii - 3 (0,98\%); Hymenolepis nana - 2 (0,65\%). Diante dessas verificações destacamos que o $B$. hominis só foi detectado pelo processo direto e pela coloração pela hematoxilina férrica, tendo sucedido plena concordância entre esses dois procedimentos. Por meio das técnicas de Faust e colaboradores e da sedimentação espontânea em água não nos deparamos com o $B$. hominis, o que demonstra a impropriedade de adotá-las quando desejada a evidenciação do citado microrganismo.

Os resultados registrados mostram a não desprezível influência de transmissão fecal-oral, a despeito de não residirem as crianças em área que contava com razoáveis recursos preventivos. Não desejamos deter-nos na análise disso, como igualmente deixaremos de tentar explicar porque verminoses apareceram em porcentagens menores, apesar de vivência em lugar semelhante. Excluímos dessa conotação o E. vermicularis, não procurado por técnica aconselhável.

Concomitância de infecções por $B$. hominis e G. lamblia seria usual. Não obstante, é preciso confirmar isso e na ilustração que relatamos apenas houve essa coincidência em duas crianças.

O método direto é singelo. Porém, por ter recebido destaque nesta orientação para diagnóstico, vale a pena rememorar como executá-lo: efetuar dois esfregaços sobre uma lâmina $(76 \times 26 \mathrm{~mm})$, estando um com solução salina fisiológica e, o outro, com solução de Lugol; empregando um palito de madeira, de sorvete por exemplo, ou bastão de vidro, fazer mistura de pequena 
quantidade de fezes primeiro na solução fisiológica e, depois, na solução de Lugol, de modo a obter preparado transparente; cobrir com lamínula (22x22mm); examinar ao microscópio, primeiramente com pequeno aumento e, a seguir, por intermédio do subseqüente maior; observar com cuidado e integralmente as preparações, incluindo na observação o sobrenadante do líqüido contido entre lâmina e lamínula; recomendamos que o palito de madeira seja mergulhado em diferentes pontos da amostra e, de preferência, nas porções que tenham muco para suceder maior eficácia do procedimento, como ainda para análise da superfície do exsudato; a técnica é econômica, pouco trabalhosa e requer bastante perícia por parte de quem a efetua; para comprovação dos tipos de protozoários evidenciados são úteis as colorações pela hematoxilina férrica ou pela tionina.

Nossa intenção básica diz respeito à difusão de uma ponderação, a um aconselhamento e a um posicionamento acerca do diagnóstico: 1) é absolutamente necessário esclarecer questões concernentes à blastocistose, exemplificadas por taxonomia, mecanismos de transmissão com elucidação dos fatores influentes, atividade oportunista, obtenção de bem satisfatório tratamento e, sobretudo, esclarecimento da patogenicidade; 2) os que têm obrigação de cuidar convenientemente da saúde pública precisam preocupar-se com essa protozoose, a fim de definir como agir em determinadas situações, até mesmo representadas por surtos de diferentes tipos;3) deve ficar claro que a utilização de comportamentos impróprios faz com que exames parasitológicos de fezes nunca evidenciem o $B$. hominis, prejudicando diagnósticos, medidas assistenciais e avaliações epidemiológicas.

É incorreto continuar abordando as controvérsias e indefinições referentes à blastocistose com pretenso fundamento em impressões ou convicções não respaldadas em documentações científicas. Pesquisas esclarecedoras não podem retardar, cabendo a parasitologistas, infectologistas e gastroenterologistas, entre outros profissionais, programá-las sem demora. Não se afigura apropriado ver prosseguimento de condutas inadequadas em atenções médicoassistenciais, diagnósticas e epidemiológicas. 